\title{
EDUCAÇÃO AMBIENTAL NO CURRÍCULO ESCOLAR DO CURSO TÉCNICO EM AGROPECUÁRIA DO INSTITUTO FEDERAL GOIANO CAMPUS RIO VERDE
}

\author{
Viviane Proto Ferreira ${ }^{1}$
}

Resumo: O presente artigo tem como objetivo analisar a percepção dos estudantes do Curso Técnico em Agropecuária do Instituto Federal Goiano Campus Rio Verde - Goiás em relação às questões ambientais. A pesquisa, numa abordagem qualitativa, utiliza como instrumento metodológico questionário estruturado direcionado aos alunos da instituição como também registros resultantes da observação da pesquisadora no cotidiano escolar. Os resultados demonstram que há uma visão conservacionista em relação à Educação Ambiental na instituição, fazendo com que ela não se coloque no exercício cotidiano da escola, ocorrendo de forma eventista. Ao final do artigo, foram elencadas sugestões de melhoria frente a este cenário.

Palavras-chave: Educação Profissional; Currículo; Questões Socioambientais.

Abstract: This article aims to analyze the perception of students of the Technical Course in Agriculture and Livestock at Instituto Federal Goiano Campus Rio Verde (GO, Btazil) in relation to environmental issues. The research, in a qualitative approach, uses as a methodological instrument a structured questionnaire directed to the students of the institution as well as records resulting from the researcher's observation in the school routine. The results demonstrate that there is a conservationist view in relation to Environmental Education in the institution, making it not to be part of the daily exercise of the school, occurring in an eventist way. At the end of the article, suggestions for improvement in this scenario were listed.

Keywords: Professional Education; Curriculum; Social and Environmental Issues.

${ }^{1}$ Instituto Federal Goiano Campus Rio Verde. E-mail: vivianeproto@yahoo.com.br. 



\section{Introdução}

A Educação Ambiental e a Educação Profissional de Nível Médio são temáticas que vêm produzindo grandes discussões e análises entre os pesquisadores dedicados à temática da educação, demandando grandes desafios para os responsáveis pela oferta de cursos nessa modalidade de ensino.

Dentre as inúmeras questões que perpassam a elaboração e implantação dos currículos escolares do Ensino Médio na Educação Profissional, uma assume, em nossa perspectiva, grande relevância, qual seja a da inserção da Educação Ambiental, como um dos temas transversais a serem implementados, pois apesar dos Parâmetros Curriculares Nacionais (PCN's), assim como a Lei n. 9.795 de 27 de abril de 1999 (Plano Nacional de Educação Ambiental), no artigo segundo, explicitarem que a questão ambiental deve ser trabalhada de forma contínua, sistemática, abrangente e integrada, em todos os níveis e modalidades do processo educativo, em caráter formal e não formal, isto muitas vezes não ocorre de maneira adequada, o que faz com que haja um distanciamento entre a Educação Ambiental e a realidade em que muitos alunos estão inseridos, especialmente, dos discentes da área de agropecuária, que tem como preceitos para a sua formação a qualidade e sustentabilidade econômica, ambiental e social.

Cabe ressaltar, que a formação profissionalizante ofertada pelos Institutos Federais de Educação, Ciência e Tecnologia que são instituições integrantes da Educação Profissional e Tecnológica, além da formação para o trabalho, visam formar cidadãos pautados nos valores humanos da igualdade, solidariedade, ética, competência, atuação solidária no mundo do trabalho e gestão do conhecimento. Sendo que, tal fato, por si, já evidencia a necessidade da preocupação com a Educação Ambiental no cotidiano dessas instituições.

Com isso, essa pesquisa tem o intuito de analisar as práticas de Educação Ambiental implementadas no Instituto Federal Goiano Campus Rio Verde, a fim de estudar as ferramentas que estão sendo utilizadas no processo formativo do Curso Técnico em Agropecuária, curso este que forma todos os anos, diversos profissionais atuantes no campo agrícola da região, assim como pretende mostrar o papel do educador como formador do aprendizado, pois introduzindo a Educação Ambiental no currículo através das mais diversas práticas pedagógicas, podemos contribuir para mudanças no comportamento de um grande número de alunos. Tendo como relevância social, a formação de indivíduos ecologicamente equilibrados e saudáveis além de defensores do meio ambiente, consequentemente agentes capazes de transformar a comunidade em que estão inseridos.

Diante do contexto apresentado, destacamos algumas questões de estudo as quais foram colocadas como forma de estimular a pesquisa: Existe, de fato, uma prática educativa e pedagógica de Educação Ambiental no Instituto Federal Goiano Campus Rio Verde? Se existe, de que forma tem se dado essa 
prática? Ocorre uma inter-relação da temática ambiental (transversalidade) no currículo da Instituição, aparecendo no seu Projeto Político Pedagógico (PPP)?

Nesse prisma, ressaltamos, ademais, que esta pesquisa se fundamenta nos marcos institucionais que configuram e normatizam a Educação Ambiental e nas práticas educativas em processo. Sendo que, ao observarmos a problemática mundial causada pelo atual modelo de desenvolvimento econômico, fruto do capitalismo e das relações sociais e de suas formas de produção tecnicista, vemos que esta contribuiu para elaboração de leis, normas e regulamentos nacionais e internacionais na tentativa de minimizar os impactos já sofridos e conscientizar para uma tomada de posição coletiva e individual com o intuito de evitar mais ações predatórias e preservar a qualidade de vida no planeta.

Já que conforme afirma Bet et al (2020, p.284), as temáticas socioambientais são urgentes e devem receber a atenção de todas as nações em prol da perenização da raça humana e das demais espécies do planeta. Portanto, a Educação Ambiental surge, nesse contexto, como elemento crítico de enfrentamento assim como uma possibilidade concreta de contribuir para um desenvolvimento social sustentável.

\section{Metodologia}

A pesquisa, de caráter qualitativo, consistiu-se de um estudo de caso, realizado no Instituto Federal Goiano Campus Rio Verde localizado na zona rural da referida cidade, no mês de setembro de 2019, com participação de 40 alunos (100\% dos estudantes presentes às aulas e maiores de 18 anos) do terceiro e quarto períodos, matutino e vespertino, do Técnico em Agropecuária, formado por alunos de ambos os sexos.

O Curso Técnico em Agropecuária foi escolhido por ser o mais antigo da instituição e por formar profissionais que trabalham com práticas agrícolas, orientando produtores rurais, sendo que estas práticas estão diretamente ligadas a impactos ambientais, o que vem de encontro com os objetivos dessa pesquisa.

A coleta de dados, para subsidiar a análise, foi realizada através de pesquisa bibliográfica a respeito da temática ambiental, além de uma sondagem inicial do curso em que seria aplicado o questionário, com a verificação da matriz curricular e Projeto Político Pedagógico (PPP). Posteriormente, foi realizada a aplicação de questionário composto por 15 questões, em sua maioria fechadas (14) e uma questão aberta, junto aos alunos dos dois últimos semestres do curso. Vale ressaltar que os questionários só foram aplicados após serem aprovados pelo Comitê de Ética em Pesquisa assim como autorizados pela Direção e Coordenação da Instituição.

O questionário foi dividido em duas partes; sendo que a primeira parte procurou obter informações do perfil dos estudantes, contendo quatro questões e a segunda parte, contendo onze perguntas, enfocou conhecimentos relativos 
à Educação Ambiental e a respeito da preocupação dos alunos em preservar e conservar o meio ambiente. Por fim, as respostas dos alunos foram tabuladas e analisadas para se obter as informações referentes ao tema do estudo.

Nos dias de aplicação do questionário, houve uma boa participação e aceitação dos alunos e professores onde deram todo apoio inclusive alguns alunos fizeram comentários sobre as suas experiências profissionais.

\section{Resultados e Discussão}

Durante a aplicação do questionário, um aspecto nos chamou a atenção, a pequena quantidade de alunos nos últimos períodos do curso, pois a oferta deste é de 50 vagas no período matutino e 50 vagas no período vespertino, sendo que apenas 8 a 12 estudantes em média concluem o curso, demonstrando assim o alto índice de evasão dele.

$\mathrm{Na}$ análise dos resultados dos perfis dos alunos, foi perguntado o sexo do estudante, a idade, sua origem (urbana ou rural), e se sua família possui propriedade rural. Constatou-se que a maioria dos alunos eram do sexo masculino (57,5\%), no entanto, o número de alunos do sexo feminino nos chamou também a atenção (42,5\%), demonstrando que as mulheres estão cada vez mais buscando sua qualificação e posição no mercado de trabalho.

Nesse prisma, podemos destacar também que as mulheres atualmente têm buscado se colocar em atividades antigamente conhecidas como "profissões masculinas". Em relação à faixa etária, observou-se que metade $(50 \%)$ era composta por alunos bem jovens entre 18 e 21 anos, demonstrando que essa faixa etária cada vez mais tem buscado se qualificar para ingressar no mercado de trabalho, a fim de conseguir uma independência financeira e profissional, sendo de conhecimento público a dificuldade que o jovem encontra nos dias atuais para conseguir o seu primeiro emprego além da dificuldade de conseguir uma vaga no mercado de trabalho sem possuir experiência prévia. Assim, o ensino técnico profissionalizante se apresenta como uma oportunidade para esses jovens. Também notamos que $(22,5 \%)$ dos alunos têm entre 35 e 45 anos, demonstrando que a idade não é empecilho para se começar a estudar e procurar uma qualificação para se colocar no mercado de trabalho.

No que tange à origem, $80 \%$ afirmaram ter origem urbana, sendo que $65 \%$ não possuem propriedade rural, deste modo, verifica-se o interesse atual de colocação no mercado de trabalho ao contrário do que ocorria antigamente em que muitas pessoas buscavam conhecimento para aplicar em suas próprias propriedades rurais.

No tocante às questões relativas à percepção ambiental, na primeira questão foi perguntado aos alunos se estes visualizam em sua futura área de atuação, atividades que possam ter impactos ambientais significativos, $60 \%$ dos alunos acreditam que sua atividade futura poderá ocasionar impactos ambientais, $25 \%$ acreditam que não e $15 \%$ não têm conhecimento para opinar 
no momento, apesar destes representarem uma minoria, este dado se mostra relevante, pois é necessário verificar quais pontos de sua formação estão falhos a fim de serem sanados, promovendo assim uma melhor habilitação e conhecimento a esses futuros profissionais.

$\mathrm{Na}$ segunda questão, foi perguntado se o conhecimento sobre a legislação ambiental dos alunos é suficiente para orientar um produtor rural sobre a adequada exploração do meio ambiente, seguindo as normas ambientais. A maioria $47,5 \%$ relataram que se sentem preparados em alguns pontos, $40 \%$ se sentem preparados e $12,5 \%$ não se sentem preparados. Assim, estes resultados são preocupantes, pois alguns aspectos da formação devem ser melhorados em relação à legislação ambiental. Inclusive ao analisar a matriz curricular do curso, das 21 disciplinas ofertadas, não observamos nenhuma disciplina específica sobre legislação ou ética, sendo que a Lei n. 9.795 referente à política nacional de Educação Ambiental, no seu artigo décimo, inciso terceiro explicita que nos cursos de formação técnico-profissional, em todos os níveis, deve ser incorporado conteúdo que trate de ética ambiental das atividades profissionais a serem desenvolvidas.

Nesse contexto, também ao analisarmos o Projeto Político Pedagógico do curso, observamos que este baseou na nova LDB, a qual não faz menção à Educação Ambiental.

Na terceira questão, foi inquirido aos estudantes se estes se preocupam com o modo que o alimento foi produzido. Do total de alunos, $82,5 \%$ responderam que se preocupam com o modo com que o alimento foi produzido ao consumi-lo e 17,5\% responderam que não. Assim, observamos um aspecto positivo na formação destes estudantes, já que estes demonstram interesse em conhecer o modo de produção alimentar, sendo que a produção orgânica no Brasil vem crescendo, correspondendo à produção que não utiliza agrotóxicos, fertilizantes solúveis, organismos geneticamente modificados e radiações ionizantes em qualquer fase do processo de produção, processamento, armazenamento, distribuição e comercialização.

Hoje, já temos 17 mil propriedades certificadas em todas as unidades da federação, sendo que a maior parte vem de pequenos produtores, o que perfaz em torno de um milhão de hectares, além disso, o consumo de produtos orgânicos cresce anualmente cerca de $25 \%$, já em relação a produção, os estados da região Sul são os que mais se destacam (SEBRAE, 2018). Em contrapartida, nunca se liberou tanto agrotóxico no país quanto no primeiro semestre de 2019. Miller e Tyler (2007, p. 258) citam que vários estudos têm demonstrado que é possível diminuir o uso de pesticidas sem comprometer a produtividade.

Na quarta questão, foi interrogado aos discentes sobre os conhecimentos abordados nas disciplinas relacionadas à Educação Ambiental, em relação às respostas, $50 \%$ dos alunos citam que os conteúdos relacionados à Educação Ambiental são abordados constantemente nas disciplinas, 25\% acham que esta é abordada de forma inexpressiva, $17,5 \%$ citam que estes conteúdos são 
abordados somente por ocasião de eventos e/ou campanhas educativas e 7,5\% responderam que a Educação Ambiental não é abordada.

Nesse sentido, numa primeira análise, pode parecer positivo o fato da Educação Ambiental ser abordada nos conteúdos das disciplinas para metade dos alunos. Contudo, para $50 \%$ esta se apresenta inexpressiva, eventista ou até não abordada, este dado se revela preocupante, pois, apesar de termos uma Política Nacional destinada à Educação Ambiental (Lei n. 9.795), a qual representa uma importante norma no corpo legislativo, esta ainda carece de aplicabilidade, tal fato, deve-se ao modelo pedagógico construído ao longo dos anos, que não enxerga a Educação Ambiental como prioridade dentro de sala de aula.

$\mathrm{Na}$ quinta questão, quisemos investigar melhor como o conteúdo relacionado à Educação Ambiental é destacado: $30 \%$ afirmam que o conteúdo é destacado de forma ecológica, $28 \%$ de forma econômica, $18 \%$ de forma cultural, $13 \%$ de forma social e 11\% dizem que a Educação Ambiental não é abordada no conteúdo.

Embora estes dados possam parecer positivos, o "dever" de agir positivamente em buscar a transformação ecológica, econômica, social e cultural que queremos cabe a todos, professores, alunos assim como a toda sociedade, além do governo e entidades nacionais e internacionais. Não podemos restringir os conteúdos ministrados à simples percepção sobre a gravidade dos problemas ambientais e às consequências vivenciadas, hoje, no mundo, sem toda a contextualização necessária.

Nesse sentido, não podemos deixar de mencionar, a abordagem da Educação Ambiental de forma conservacionista somente em seu aspecto ecológico, como muitas vezes, vem ocorrendo, esquecendo-se de abranger todos os campos envolvidos que dizem respeito aos aspectos econômicos, sociais, culturais e políticos. Neste ponto, é necessário destacar como aponta Carvalho (1995, p.60), que não é possível o enfrentamento de um só campo, é preciso a junção de normas e princípios legais; estímulos econômicos e fiscais; mobilização da opinião pública e associações civis; contribuição da pesquisa científica e da iniciativa dos organismos nacionais e internacionais através de políticas públicas favoráveis à qualidade e a defesa da vida.

$\mathrm{Na}$ sexta questão, foi questionado em relação aos conhecimentos relacionados ao consumo sustentável se são ou não abordados nas disciplinas. $57,5 \%$ afirmam que os conhecimentos relacionados ao consumo sustentável vêm sendo abordados de forma inexpressiva, $40 \%$ mencionam que vêm sendo abordados constantemente e $2,5 \%$ dizem que não são abordados. Nesse sentido, podemos considerar que esses conteúdos poderiam ser mais trabalhados já que a maioria ainda acredita que vêm sendo trabalhados de forma inexpressiva.

Na sétima questão, foi perguntado aos alunos se os mesmos promovem a coleta seletiva de lixo e em qual local. A maioria dos alunos $47,5 \%$ afirmam 
que não promovem a coleta seletiva de lixo nem na escola nem fora dela, $37,5 \%$ mencionam que promovem na escola e na comunidade, $10 \%$ ressaltam que promovem somente na comunidade e $5 \%$ que promovem somente na escola.

Atualmente, o Instituto Federal Goiano Campus Rio Verde conta com dois tipos de lixeiras espalhadas pelo Campus, uma para material orgânico e outra para inorgânico.

Embora seja uma importante iniciativa, cabe destacar que esse tema merece ser mais divulgado, discutido e incentivado na instituição. Além disso, Carvalho (1995, p.59) assevera que atualmente há uma tendência a relacionar problemas relacionados ao consumo com a destinação do lixo, reciclagem, em detrimento dos problemas ligados à esfera da produção.

$\mathrm{Na}$ oitava questão, foi inquirido aos alunos, se o Instituto Federal Goiano Campus Rio Verde promove a reciclagem e/ou reaproveitamento de materiais orgânicos e inorgânicos. A maioria dos alunos $80 \%$ afirmam que a instituição promove a reciclagem e/ou reaproveitamento de materiais orgânicos e inorgânicos, $20 \%$ apontam que não. Tivemos a oportunidade de corroborar esta afirmativa, já que nos setores da fazenda da instituição é realizada a fabricação de adubos orgânicos que são utilizados nos canteiros da horta da escola, sendo que estes compostos orgânicos se apresentam como excelente forma de reaproveitamento de restos animais e vegetais. Além disso, os discentes do Curso Técnico em Agropecuária possuem aulas teóricas e práticas a esse respeito, aprendendo o passo a passo para sua fabricação.

$\mathrm{Na}$ nona questão, foi perguntado aos estudantes, se a instituição promove ações de educação e preservação ambiental além da reciclagem. A maioria dos alunos $57,5 \%$ indicaram que a instituição não promove ações de educação e preservação ambiental, já para $42,5 \%$ promove. Lembramos que esta era a única questão aberta do questionário. No entanto, não conseguindo visualizar nenhum dado novo, já que os que responderam afirmativamente a questão citaram: realização de palestras, presença de lixeira e postos de coleta na instituição e o reaproveitamento de matéria orgânica para produção de adubos, itens esses já citados anteriormente.

Esses resultados nos permitiram observar que na visão dos alunos muitas vezes a temática ambiental ainda é abordada de forma esporádica. Dias (1992, p.89) corrobora com este pensamento, ao afirmar que é necessário uma proposta de Educação Ambiental que busque o enfrentamento da crise atual de forma contínua, contemplando o cidadão em todas as fases da vida, de caráter interdisciplinar, integrando as diferentes áreas do conhecimento, de perfil pluridimensional, associando aspectos econômicos, políticos, culturais, sociais e ecológicos, voltada para a participação social e para solução dos problemas ambientais, além de visar mudanças de valores, comportamentos e atitudes. Por isso, é necessário que os educadores promovam um maior envolvimento de alunos, estimulando mudanças de atitudes, valores e, principalmente, em desenvolver o pensamento crítico. 
$\mathrm{Na}$ décima questão, foi perguntado aos alunos em relação aos conhecimentos adquiridos, se estes contribuíram para seu comportamento em relação às questões ambientais. A maioria dos estudantes 55\% acreditam que sim, que os conhecimentos adquiridos no curso contribuíram para seu comportamento em relação às questões ambientais, $45 \%$ acreditam que em parte. Apesar da maioria dos discentes afirmarem que os conhecimentos adquiridos promoveram uma maior conscientização em relação às questões ambientais, acreditamos que esta temática poderia estar mais presente nos conteúdos das disciplinas assim como poderia ser trabalhada de forma interdisciplinar.

$\mathrm{Na}$ décima primeira questão, foi perguntado aos alunos se estes acreditam que são capazes de aplicar os conhecimentos adquiridos em suas futuras atividades profissionais após a conclusão do curso. A maioria dos alunos, $70 \%$, acreditam que tem capacidade para aplicar os conhecimentos adquiridos no curso em suas futuras atividades profissionais. Já $27,5 \%$ indicaram que conseguem aplicar de forma precária e somente 2,5\% não acreditam que estejam aptos a aplicá-los. Apesar da maioria acreditar que tem condições de aplicar os conhecimentos adquiridos, tendo em vista as respostas às questões anteriores, acreditamos que a Educação Ambiental poderia estar presente de forma mais efetiva no Projeto Político Pedagógico do curso, de modo a permitir a criação e manutenção de mais espaços dialógicos entre alunos, professores e servidores da instituição com envolvimento de pais e membros da sociedade nessa discussão, proposição de encontros e assembleias em que todos pudessem propor mais ações sustentáveis. Enfim, que colocassem a Educação Ambiental como prática contínua, cotidiana e crítica na comunidade escolar.

Desta forma, ao analisarmos a matriz curricular do curso, observamos que apesar desta ter sido elaborada, visando uma boa qualificação a estes futuros profissionais, seria necessário uma maior integração entre as disciplinas, promovendo uma maior interdisciplinaridade, assim como uma maior integração entre os professores que ministram disciplinas no Curso Técnico em Agropecuária, desenvolvendo projetos e envolvendo os alunos, pois como foi analisado anteriormente, pontos como reciclagem, consumo sustentável e legislação ambiental ainda deixam a desejar.

Assim, acreditamos que às 160 horas de estágio obrigatório e 40 horas de atividades extracurriculares, obrigatórias do curso, seriam uma boa alternativa para esse maior envolvimento dos estudantes.

Além disso, após a aplicação dos questionários, buscamos observar quais outras ações relativas à Educação Ambiental vêm sendo desenvolvidas na instituição, fizemos isso, visitando alguns setores e conversando informalmente com servidores, professores e alunos. Observamos que existem alguns projetos que vêm ocorrendo no momento, como o projeto caneca, o qual faz parte da Agenda da Administração Pública Federal, em que foram doadas canecas de plástico para alunos e servidores, a fim de diminuir o consumo de copos descartáveis. Assim como o projeto de doação de mudas a fim de promover o

revista brasileira educação ambiental 
reflorestamento e a recuperação de áreas degradadas da Região Sudoeste do estado de Goiás. Também vêm sendo desenvolvido, o projeto do Jardim Botânico de Rio Verde, que tem por objetivo a preservação de espécies, conservação da biodiversidade, realização de pesquisas, melhoria da qualidade de vida urbana, além da promoção da Educação Ambiental e do lazer, o qual promove a integração entre os alunos e professores do instituto com os alunos de outras escolas da região, durante a realização de visitas e laboratórios itinerantes guiados a fim de conhecer suas instalações. No entanto, observamos que estes projetos se mostram de maneira isolada, faltando maior divulgação e integração dos estudantes.

\section{Considerações Finais}

Essa pesquisa utilizou-se de uma abordagem qualitativa de caráter descritivo, buscando verificar a percepção dos alunos do Curso Técnico em Agropecuária do Instituto Federal Goiano Campus Rio Verde em relação às questões ambientais, para isso, foram aplicados questionários, a fim de averiguar de que forma essa percepção se dá.

Observamos que apesar do grande interesse demonstrado pelos alunos sobre às questões ambientais e de possuir um quadro de professores com excelente formação acadêmica, ainda nos deparamos com uma visão conservacionista em relação a Educação Ambiental, além de um distanciamento entre teoria e prática, algo bem diferente do que é explicitado como esperado no Projeto Político Pedagógico do curso.

Assim, com base no estudo realizado, podemos afirmar que se faz necessário investir mais na gestão pedagógica e ambiental no Instituto Federal Goiano Campus Rio Verde para que tenhamos a efetivação de uma prática, ambientalmente, sustentável.

Antes de iniciar a pesquisa, colocamos algumas questões a fim de nortear o estudo: Existe uma prática educativa e pedagógica de Educação Ambiental no Instituto Federal Goiano Campus Rio Verde? Se sim, como tem se dado essa prática? Existe uma inter-relação (transversalidade) do currículo com seu Projeto Político Pedagógico?

Respondendo essas questões, Pletsch (2010, p. 158) esclarece que "a prática pedagógica institucionalizada se refere à atividade docente realizada nos sistemas educacionais e às organizações escolares em que estão inseridos. Neste sentido, "a prática profissional depende das decisões individuais, que não estão isentas da influência de normas coletivas $e$ de regulações organizacionais". Assim, a prática pedagógica não pode se limitar somente as ações do professor em sala de aula. No entanto, foi o que mais observamos durante a realização da pesquisa, que está muito limitada ao interesse do professor pela temática ambiental, inserindo esses conteúdos em sala de aula, muitas vezes, tendo mais caráter informativo do que formativo. 
Destacamos que a ambientalização curricular é um processo contínuo de produção cultural voltado à formação de profissionais comprometidos com a busca permanente das melhores relações possíveis entre a sociedade e a natureza, atendendo aos valores da justiça, solidariedade e da equidade, aplicando os princípios éticos universalmente reconhecidos e o respeito às diversidades (Rede ACESS, 2002).

Ademais, os estudos sobre ambientalização curricular são desafiadores e estão relacionados a todos os níveis e modalidades de ensino, pois trata-se de verificar em que perspectiva a questão ambiental se apresenta na formação de crianças, adolescentes e jovens e quais as necessárias construções e reformulações curriculares precisam ser efetivadas em prol de uma formação integral e integradora.

Já ao que diz respeito à interdisciplinaridade entre as disciplinas presentes na matriz curricular, esta não vem ocorrendo, observando-se que existem muitas disciplinas destinadas à formação técnica especializada, mas sem relação entre si.

Nessa concepção, é necessária uma integração recíproca entre as várias disciplinas e campos do conhecimento através de um eixo central, um pensar organizador que promova essa integração, até mesmo uma transdisciplinaridade, a exemplo da ecologia que se utiliza de várias ciências (biologia, geografia, botânica, dentre outras) para constituir uma unidade complexa a ser estudada. Já que uma disciplina isolada na matriz curricular dedicada à Educação Ambiental não é capaz de promover isso, segundo vários estudiosos e a própria legislação destaquem esse ponto.

Dessa forma, apesar do enfoque desta pesquisa se concentrar na percepção dos alunos, é importante que o professor se faça o seguinte questionamento: Será que eu atuo/contribuo, de forma efetiva, na construção do ensino inter/transdisciplinar na formação de profissionais das áreas agrárias e ambientais? Pois estes questionamentos poderão servir de base para estudos posteriores que envolvam a perspectiva docente diante da formação de técnicos de nível médio no cenário do agronegócio da região centro-oeste do país. Além do que os questionamentos suscitados por esta pesquisa poderão acenar para outras possibilidades investigativas que contribuam para análise de ações de Educação Ambiental no contexto escolar da atualidade.

Consequentemente, podemos afirmar por meio das leituras realizadas, do referencial teórico, da legislação relativa à Educação Ambiental, dos resultados dos questionários e das observações realizadas que há uma prática educativa, mas que infelizmente está dissociada do Projeto Político Pedagógico do curso e de uma visão crítica e engajada com a Educação Ambiental.

Já em no que tange à percepção dos alunos do Curso Técnico em Agropecuária em serem futuros educadores ambientais, esta é uma questão que ainda precisa ser mais bem trabalhada, já que a formação de educadores ambientais no Brasil deve direcionar a uma intervenção educacional cidadã e 
disposta em buscar soluções para desenvolver sociedades sustentáveis, ainda é um processo longo e que permanece em construção.

No que diz respeito aos problemas ambientais locais, podemos notar que não existe no momento nenhuma prática socioambiental ou projeto sendo desenvolvido voltado para os produtores e agricultores rurais da região. Por esta razão, é importante destacar que para que possa existir um caráter formativo e não informativo acerca das questões ambientais, as temáticas que são significativas no âmbito local, devem ser o ponto de partida para uma análise crítica da realidade socioambiental mais abrangente.

Assim, por fim, gostaríamos de elencar algumas sugestões de melhorias em relação ao curso, tais como inovações nos conteúdos conceituais, metodológicos e atitudinais com a presença do enfoque interdisciplinar do currículo; compreensão da complexidade e visão sistêmica das questões ambientais com soluções proativas, a exemplo, projetos; transversalidade da questão ambiental; integração da área ambiental com o campo de atuação do curso; promoção da formação docente; coleta de sugestões e ajustes de trabalho com os docentes para identificar oportunidades; workshops, reuniões de colegiado e formação de grupo de trabalho para ambientalização do curso, inserção dos demais servidores, dos pais e da comunidade em geral nas reuniões, a fim de integrá-los na discussão.

Assim, esperamos que esta pesquisa tenha contribuído para despertar de alguma forma uma maior consciência nos futuros profissionais técnicos em agropecuária sobre a importância da sua atuação no mercado de trabalho, principalmente, sobre a importância de uma postura cidadã e de responsabilidade ambiental.

Ademais, esperamos também que possa contribuir para que os professores e gestores busquem refletir acerca do Projeto Político Pedagógico e da proposta curricular do curso, na sua real efetivação e nas diferentes possibilidades que estão postas para a oferta de uma formação profissional beminformada sobre as questões da atualidade e com os desafios que elas apresentam.

Entendemos que este desafio é de todos nós, alunos, professores e pais, sendo necessário seguir adiante na busca da construção de uma sociedade melhor e sustentável para todos, sobretudo, quando se acirram as questões nacionais e globais que colocam em risco a sobrevivência planetária.

\section{Referências}

BET, L. G.; PRADO, R.; PRADO, M.; BENAQUE, H. P. (2020). Educação Ambiental aplicada à gestão de resíduos sólidos: a iniciativa inovadora do Programa Condomínio Sustentável. Revista Brasileira de Educação Ambiental (RevBEA), 15(5), 282-298. 
BRASIL. LDB. Diretrizes e Bases da Educação Nacional: Lei n. 9.394 de 1996, que estabelece as diretrizes e bases da educação nacional; e legislação correlata. Brasília: Câmara dos Deputados, Coordenação de Publicações, 2001.

BRASIL. Parâmetros Curriculares Nacionais. MEC, 2º ed. Brasília:1996.

BRASIL. Política Nacional de Educação Ambiental. Lei n. 9.795, de 27 de abril de 1999.

CARVALHO, I. C. M. Movimentos sociais e políticas de meio ambiente. A Educação Ambiental onde fica? In: SORRENTINO, M.; TRAJBER, R.; BRAGA, T. (orgs). Cadernos do III Fórum de Educação Ambiental. São Paulo: Gaia, p. 58-62, 1995.

DIAS, G. F. Educação Ambiental, princípios e práticas. São Paulo: Gaia, 399p, 1992.

MILLER, G. T.; TYLER, G. M. Ciência ambiental: tradução All Tasks; revisão técnica Welington Braz Carvalho Delitti. - São Paulo: Thomson Learning, 2007.

PLETSCH, M. D. Repensando a inclusão escolar: diretrizes políticas, práticas curriculares e deficiência intelectual. Editora EDUR/NAU, Rio de Janeiro. (Serie Docência.doc), 2010.

REDE ACESS. Red de Ambientalización Curricular de los Estudios Superiores. $2002 . \quad$ Disponível em: $<$ http://insma.udg.es/ambientalitzacio/web alfastinas/castella/c index.htm>. Acesso em: 15 out. 2019.

SEBRAE. Disponível em: $<$ https://www.sebrae.com.br/sites/PortalSebrae/artigos/o-que-e-agriculturaorganica,69d9438af1c92410VgnVCM100000b272010aRCRD>. Acesso em 10/01/2020. 